\title{
Knowledge Gap and Poor Satisfaction as Barriers to Hand Hygiene in a Teaching Hospital in South-South Nigeria
}

\author{
Agantem Emmanuel Ekuma ${ }^{1,3}$, Olugbemi Oluseyi Motilewa ${ }^{2}$, Nsini Faith Isong ${ }^{3}$ \\ ${ }^{1}$ Department of Medical Microbiology and Parasitology, University of Uyo, Uyo, Nigeria \\ ${ }^{2}$ Department of Community Health, University of Uyo and University of Uyo Teaching Hospital, Uyo, Nigeria \\ ${ }^{3}$ Department of Medical Microbiology and Parasitology, University of Uyo Teaching Hospital, Uyo, Nigeria
}

Email address:

agantemekuma@uniuyo.edu.ng (A. E. Ekuma)

\section{To cite this article:}

Agantem Emmanuel Ekuma, Olugbemi Oluseyi Motilewa, Nsini Faith Isong. Knowledge Gap and Poor Satisfaction as Barriers to Hand Hygiene in a Teaching Hospital in South-South Nigeria. Central African Journal of Public Health. Vol. 5, No. 3, 2019 , pp. $109-112$. doi: $10.11648 /$ j.cajph.20190503.12

Received: February 7, 2019; Accepted: March 12, 2019; Published: April 2, 2019

\begin{abstract}
Health care associated infection remains a global problem and hand hygiene has been identified as an effective strategy for its control. Adherence to hand hygiene among healthcare workers, however, is low across the world. The aim of this study was to determine the level of knowledge of hand hygiene among healthcare workers and identify reasons for poor hand hygiene practice in our hospital. A 19-point questionnaire was administered to available health workers in February 2018 to assess availability of hand hygiene materials, frequency of performing hand hygiene, satisfaction with hand hygiene materials, and knowledge of infection transmission dynamics, efficacy and proper use of hand hygiene methods. Eighty-five healthcare workers participated in this study. Mean knowledge score of participants was $37.87 \pm 13.45$. Most participants reported performing hand hygiene up to $90 \%$ of the time and there were high rates of dissatisfaction among participants with hand hygiene products and their availability. This study shows that there is poor knowledge of some aspects of hand hygiene among healthcare workers in our hospital and there is general dissatisfaction with current hand hygiene products.
\end{abstract}

Keywords: Hand Hygiene, Knowledge, Satisfaction, Nigeria

\section{Introduction}

Hand hygiene, defined as either washing the hands with soap and water or hand antisepsis with an alcohol-based hand-rub, [1] has been described as the single most important practice to reduce the transmission of infectious agents in healthcare settings. [2] In hospitals, spread of infectious agents occur mainly through hands of caregivers. [3] Historically, institution of handwashing was associated with reduced incidence of puerperal sepsis in a maternity ward. [4] Healthcare associated infections (HAI) are responsible for thousands of deaths worldwide every year. In developed countries HAI affects from $5 \%$ to $15 \%$ of hospitalized patients in regular wards and as many as $50 \%$ or more of patients in intensive care units (ICUs) while in developing countries, the magnitude of the problem remains underestimated or even unknown largely because HAI diagnosis is complex and surveillance activities to guide interventions require expertise and resources. [5] The pooled prevalence in mixed patient populations of HAI in low- and middle-income countries was found to range from $10.1 \%$ to $15.5 \%$. [6]

In spite of this, studies continue to show that rates of adherence to hand hygiene among healthcare workers is low. [2, 7-9] One major reason for low adherence levels is poor knowledge among healthcare workers of risks and procedures. [10] Raising the level of knowledge of healthcare workers on transmission of infection and hand hygiene can be seen as a first step towards improving practice in this regard. [11] Consequently, education and training are recommended because they promote adherence. $[12,13]$

Lack of appropriate equipment has also been identified as another major obstacle to adherence with hand hygiene measures among healthcare workers [10, 14] especially in resource limited settings. In Italy, availability of hand hygiene products in wards was found to be associated with increased hand hygiene compliance. [15] Increasing 
availability of Alcohol Hand Sanitizers has also been noted to have the potential to address other barriers to hand hygiene. [14].

We conducted this survey to determine the level of knowledge of hand hygiene among healthcare workers and identify reasons for poor hand hygiene practice in our hospital in preparation for the introduction of a locally produced hand sanitizer to promote hand hygiene.

\section{Methods}

\subsection{Study Design and Study Area}

This was a cross sectional survey conducted at a 500-bed tertiary hospital serving a population of about five million people in Akwa Ibom and neighbouring states in Southern Nigeria. The staff strength of this facility includes 450 nurses and 420 doctors.

\subsection{Study Instrument and Study Participants}

The study instrument was a structured self-administered 19-point questionnaire which was adapted from the WHO "Saves Lives" Hand Hygiene Knowledge Questionnaire for Healthcare Workers (2009). It was administered to all health workers available in the main wards of the hospital in the month of February 2018. Questions covered availability of hand hygiene materials, frequency of performing hand hygiene, satisfaction with hand hygiene materials, and knowledge of infection transmission dynamics, efficacy and proper use of hand hygiene methods.

\subsection{Data Analysis}

Knowledge questions were structured as best answer questions or true/false (or yes/no) questions. For each correct answer, one point was awarded and overall scores were expressed in percentage. Satisfaction questions were graded on a scale of 1-10 and recoded as 1-3 not satisfied, 4-6 neither satisfied nor dissatisfied and 7-10 dissatisfied. Data was entered and analyzed using IBM Statistical Package for Social Sciences (SPSS) version 22 and summarized using proportions/percentages and presented using frequency tables.

\subsection{Ethical Considerations}

Informed consent was obtained from participants. Ethical approval was not sought as hospital patients were not included in this study.

\section{Results}

\subsection{Participants}

Eighty-five healthcare workers participated in this study most of whom were female nurses $(87.1 \%)$. Their departments are shown in figure 1 . Majority of respondents $(88.2 \%)$ reported having received previous training on hand hygiene.

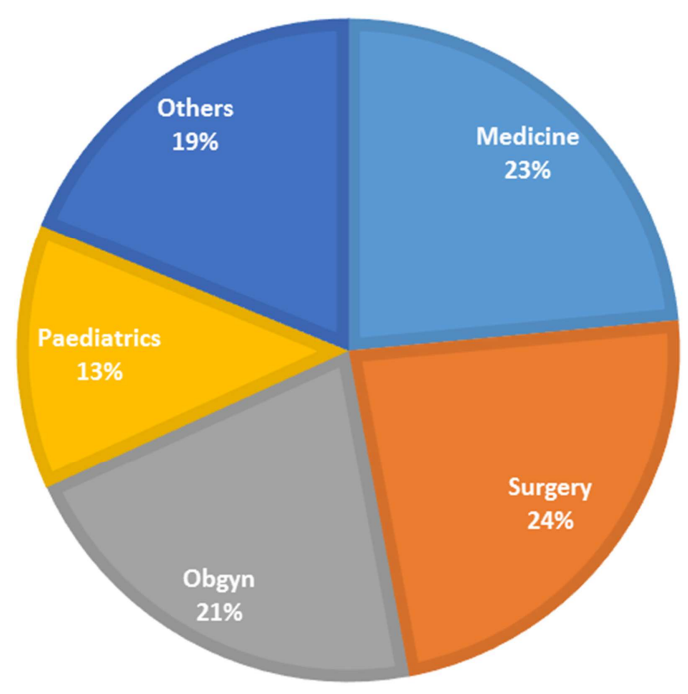

Figure 1. Department of study participants.

\subsection{Knowledge}

The scores of participants ranged from $3.23 \%$ to $70.97 \%$ with a mean score of $37.87 \pm 13.45$ and a median score of 38.70 (Table 1). The knowledge of transmission of infectious agents was generally low particularly the question about the most common source of germs associated with healthcareassociated infections. Knowledge of hand hygiene had relatively higher scores but there were some questions with low rate of correct answers. Among the questions on selection of hand hygiene products, only two had rate of correct answers above $50 \%$.

Table 1. Hand hygiene Knowledge scores of participants by section.

\begin{tabular}{lllll}
\hline Statistic & Total score & Transmission of infectious agents & Hand hygiene & Selection of appropriate hand hygiene product \\
\hline Mean & 38.33 & 28.57 & 57.58 & 27.38 \\
Median & 38.71 & 33.33 & 63.64 & 28.57 \\
Std. Deviation & 12.87 & 14.77 & 23.84 & 14.91 \\
Minimum & 3.23 & 0.00 & 9.09 & 0.00 \\
Maximum & 70.97 & 66.67 & 90.91 & 64.29 \\
\hline
\end{tabular}

\subsection{Practice}

Majority of participants $(58.8 \%)$ reported performing hand hygiene up to $90 \%$ of the time after touching contaminated surfaces (Table 2). The major reasons for not performing hand hygiene reported by participants were "Alcohol hand rub is not usually available" (49.4\%), "Heavy workload" 
(24.7\%) and "Already used gloves" (8.2\%) (Table 3). Majority of participants (56.5\%) agreed that introduction of sanctions would increase compliance with hand hygiene.

Table 2. Frequency of Cleaning Hand.

\begin{tabular}{ll}
\hline Frequency of hand hygiene & No $(\%)$ \\
\hline $25 \%$ & $3(3.5)$ \\
$50 \%$ & $6(7.1)$ \\
$75 \%$ & $18(21.2)$ \\
$90 \%$ & $50(58.8)$ \\
$100 \%$ & $8(9.4)$ \\
\hline
\end{tabular}

Table 3. Major reasons for non-performance of hand hygiene by participants.

\begin{tabular}{ll}
\hline Reason & No. (\%) \\
\hline Alcohol hand rub is not usually available & $42(49.4)$ \\
Heavy workload (too busy) & $21(24.7)$ \\
Hand rubs are poorly located & $6(7.1)$ \\
Hands don't look dirty & $2(2.4)$ \\
\hline
\end{tabular}

\subsection{Satisfaction Survey}

There were high rates of dissatisfaction among participants with $66.7 \%$ dissatisfied with hand hygiene products and $77.4 \%$ dissatisfied with availability of hand hygiene products (table 4). The most commonly available hand hygiene products according to participants were non-antibacterial soap $(32.9 \%)$, alcohol hand rub carried by individuals (24.7\%) and antibacterial soap (17.7\%) (Table 5).

Table 4. Satisfaction of participants with hand hygiene products and availability.

\begin{tabular}{lll}
\hline & $\begin{array}{l}\text { Satisfaction with } \\
\text { products }\end{array}$ & $\begin{array}{l}\text { Satisfaction with } \\
\text { availability }\end{array}$ \\
\cline { 2 - 3 } & NO. (\%) & NO. (\%) \\
\hline Yes & $5(6.0)$ & $3(3.6)$ \\
Neither satisfied nor dissatisfied & $20(23.8)$ & $14(16.7)$ \\
No & $56(66.7)$ & $65(77.4)$ \\
No response & $3(3.6)$ & $2(2.4)$ \\
\hline
\end{tabular}

Table 5. Available hand hygiene products reported by participants.

\begin{tabular}{ll}
\hline Product & No. (\%) \\
\hline Non-Antibacterial Soap & $28(32.9)$ \\
Individual Alcohol hand rub & $21(24.7)$ \\
Antibacterial soap & $15(17.7)$ \\
Hand lotion & $10(11.8)$ \\
Alcohol hand rub & $(4.7)$ \\
\hline
\end{tabular}

\section{Discussion}

In this study, we found that knowledge of healthcare workers varied in different aspects of hand hygiene. While knowledge on general hand hygiene was fair, knowledge of transmission of infections and selection of hand hygiene was much lower. This finding highlights the tilted nature of hand hygiene trainings which focus more on performance but fail to address the science underlying hand hygiene practice. Among healthcare workers, these gaps in knowledge could lead to lower compliance with hand hygiene protocol as lack of scientific information of definitive impact of improved hand hygiene on health-care-associated infection rates has been found to be a factor associated with poor adherence to hand hygiene guidelines. [16] One possible consequence of poor understanding of the rationale for hand hygiene is the finding from several studies that more healthcare workers perform hand hygiene after patient contact than before patient contact. [9, 17-19]

Participants in this study also performed poorly in selection of proper hand hygiene methods for different situations. Different modalities for hand hygiene viz hand washing and hand rubbing are appropriate in different situations and healthcare workers' ability to select the correct method for each situation is key to effective hand hygiene.

Although most participants reported high levels of compliance with hand hygiene, it has been found that in surveys of healthcare personnel, self-reported adherence are usually generally higher than that reported in observational studies. [12] Moreover, healthcare workers perception of their compliance being better than it actually is, has been identified as a barrier to hand hygiene compliance among physicians. [20]

In this study we found low satisfaction with hand hygiene materials available in the hospital. Alcohol hand rubs and antibacterial soap were reported to be less available than non-antibacterial soaps. It is well established that alcohol-based hand rubs are the most efficacious agents for reducing the number of bacteria on the hands of personnel, followed by antiseptic soaps and detergents, and non-antimicrobial soaps are the least effective. [2] Alcohol hand rub are largely unavailable in most hospitals in Nigeria due to cost constraints. A recent development looking to mitigate this in Nigeria is inhouse production of alcohol-based hand sanitizers. [21] This has the potential to reduce cost and improve availability of hand hygiene materials.

A slight majority of participants in this study were in favour of the use of sanctions and rewards to improve compliance with hand hygiene in the hospital. Administrative sanctions for non-compliance together with rewards for compliance is one of the newer strategies for improving adherence to hand hygiene. [22] The absence of these sanctions and incentives may pose a barrier to appropriate hand hygiene. $[2,18]$

\section{Conclusion}

This study shows that there is deficiency in knowledge in certain areas of hand hygiene among healthcare workers in our hospital. There is also general dissatisfaction with current hand hygiene products. This justifies the need for the intended introduction of locally produced hand sanitizer which will be more available due to reduced cost.

\section{Acknowledgements}

We gratefully acknowledge Felicia Essien and Udeme Edet 
of the UUTH Infection control unit for collecting the data for this study.

\section{Conflict of Interest Statement}

The authors declare that there is no conflict of interest.

\section{Contribution of the Author}

AEE was involved in the concept and design of the study, data acquisition and analysis and drafting of manuscript. OBM was involved in design of the study, data analysis revision of manuscript. NFI was involved in the concept and design of the study and revision of manuscript.

\section{References}

[1] Shimazaki Y. Hand hygiene. In: Infection preventive on facility for the elderly. Aichi: Nissokenz; 2005. p. 16-21.

[2] Centers for Disease Control and Prevention. Guideline for Hand Hygiene in Health-Care Settings: Recommendations of the Healthcare Infection Control Practices Advisory Committee and the HICPAC/SHEA/APIC/IDSA Hand Hygiene Task Force. Morb Mortal Wkly Rep. 2002; 51(RR16):1.

[3] Trampuz A, Widmer AF. Hand Hygiene: A frequently missed lifesaving opportunity during patient care. Mayo Clin Proc. 2004; 79:109-16.

[4] Daniels IR, Rees BI. Handwashing: simple, but effective. Ann R Coll Surg Engl. 1999; 81:117-8.

[5] Nejad SB, Allegranzi B, Syed SB, Ellis B, Pittet D. Healthcare-associated infection in Africa: a systematic review. Bull World Health Organ. 2011; 89:757-65.

[6] World Health Organization. Report on the Burden of Endemic Health Care-Associated Infection Worldwide. 2011.

[7] Nabavi M, Alavi-Moghaddam M, Gachkar L, Moeinian M. Knowledge, Attitudes, and Practices Study on Hand Hygiene Among Imam Hossein Hospital's Residents in 2013. Iran Red Crescent Med J. 2015; 17(10): e19606.

[8] Pittet D, Mourouga P, Pemeger T V. Compliance with hand washing in a teaching hospital infection control programme. Ann Intern Med. 1999; 130:126-30.

[9] Tobin EA, Asogun D, Odia I, Ehidiamen G. Knowledge and practice of infection control among health workers in a tertiary hospital in Edo state, Nigeria. Direct Res J Heal Pharmacol. 2013; 1(2):20-7.

[10] Ekwere TA, Okafor IP. Hand hygiene knowledge and practices among healthcare providers in a tertiary hospital, South West Nigeria. Int J Infect Control. 2003; 9(i14):1-10.

[11] Zakeri H, Ahmadi F, Rafeemanesh E, Saleh LA. The knowledge of hand hygiene among the healthcare workers of two teaching hospitals in Mashhad. Electron Physician. 2017; 9(8):5159-65.

[12] Siegel JD, Rhinehart E, Jackson M, Chiarello L, The Healthcare Infection Control Practices Advisory Committee. 2007 Guideline for Isolation Precautions: Preventing Transmission of Infectious Agents in Healthcare Settings. 2007.

[13] Lee SS, Park SJ, Chung MJ, Lee JH, Kang HJ, Lee J, et al. Improved Hand Hygiene Compliance is Associated with the Change of Perception toward Hand Hygiene among Medical Personnel. Infect Chemother. 2014; 46(3):165-71.

[14] Anderson MEC, Weese JS. Self-reported hand hygiene perceptions and barriers among companion animal veterinary clinic personnel in Ontario, Canada. Can Vet J. 2016; 57:2828.

[15] Moro ML, Morsillo F, Nascetti S, Parenti M, Allegranzi B, Pompa MG, et al. Determinants of success and sustainability of the WHO multimodal hand hygiene promotion campaign, Italy, 2007-2008 and 2014. Euro Surveill. 2017; 22(23):30546.

[16] Pittet D. Improving compliance with hand hygiene in hospitals. Infect Control Hosp Epidemiol. 2000; 21:381-6.

[17] Scheithauer S, Kamerseder V, Petersen P, Brokmann JC, Mach $\mathrm{C}$, Schulze-röbbecke $\mathrm{R}$, et al. Improving hand hygiene compliance in the emergency department: getting to the point. BMC Infect Dis. 2013; 13:367.

[18] Teker B, Ogutlu A, Gozdas HT, Ruayercan S, Hacialioglu G, Karabay O. Factors Affecting Hand Hygiene Adherence at a Private Hospital in Turkey. Eurasian J Med. 2015; 47:208-12.

[19] Fitzpatrick KR, Pantle AC, Mclaws M, Hughes CF, Medical T. Culture change for hand hygiene: Clean hands save lives, Part II. Med J Aust. 2009; 191(8): s13-17.

[20] Squires JE, Suh KN, Linklater S, Bruce N, Gartke K, Graham ID, et al. Improving physician hand hygiene compliance using behavioural theories: a study protocol. Implement Sci [Internet]. Implementation Science; 2013; 8(1):16. Available from: Implementation Science.

[21] Kama-Kieghe S. Local Production of Alcohol Based Hand Rubs (ABHR) in Nigeria - The Way of the Future? [Internet]. Infection control.tips. 2018 [cited 2018 Nov 19]. p. 1-5. Available from: https://infectioncontrol.tips/2016/03/05/abhr/.

[22] McInnes E, Phillips R, Middleton S, Gould D. A qualitative study of senior hospital managers' views on current and innovative strategies to improve hand hygiene. BMC Infect Dis. 2014; 14:611. 